\title{
Lectin pathway of complement activation and relation with clinical complications in critically ill children
}

\author{
Catherine Ingels', Ilse Vanhorebeek', Rudi Steffensen², Inge Derese', Lisbeth Jensen ${ }^{3}$, Pieter J. Wouters', Greet Hermans', \\ Steffen Thiel ${ }^{3}$ and Greet Van den Berghe ${ }^{1}$
}

BACKGROUND: Critically ill children are susceptible to nosocomial infections, which contribute to adverse outcomes. Deficiencies in the innate immunity lectin pathway of complement activation are implicated in a child's vulnerability to infections in conditions such as cancer, but the role during critical illness remains unclear. We hypothesized that low on-admission levels of the pathway proteins are, in part, genetically determined and associated with susceptibility to infectious complications and adverse outcomes.

METHODS: We studied protein levels of mannose-binding lectin (MBL), H-ficolin and M-ficolin, three MBL-associatedserine proteases (MASPs) and MBL-associated protein (MAp44), and relation with functional genetic polymorphisms, in 130 healthy children and upon intensive care unit (ICU) admission in 700 critically ill children of a randomized study on glycemic control.

RESULTS: Levels of MASP-1, MASP-2, MASP-3, and MAp44 were lower and the levels of $\mathrm{M}$-ficolin were higher in ICU patients on admission than those in matched healthy controls. Only a low on-admission MASP-3 level was independently associated with risk of new ICU infections and prolonged ICU stay, after correcting for other risk factors. On-admission MASP-3 varied with age, illness severity, and genetic variation.

CONCLUSION: Low on-admission MASP-3 levels in critically ill children were independently associated with subsequent acquisition of infection and prolonged ICU stay. The biological explanation needs further investigation.

hildren are admitted to the intensive care unit (ICU) most often after major or life-threatening surgery, extensive trauma, or serious infection. Clinically diagnosed nosocomial infection is a substantial problem occurring in $\sim 30 \%$ of these patients (1). Systemic inflammation, evoked by insults such as infection, trauma, surgery, and ischemia-reperfusion injury, is another serious complication associated with high morbidity (2). The question why some patients are more susceptible to developing these complications than others is intriguing and raises the possibility of genetic predisposition. Certain genetic variants of innate immunity genes would thus orchestrate different responses to apparently similar insults $(3,4)$.

The innate immune system represents the immediate response toward injury, before amplification of the adaptive immune system. Part of innate immunity is started when membrane-bound, soluble, or intracellular receptor proteins recognize highly conserved pathogen- or danger-associated molecular patterns (5). Mannose-binding lectin (MBL), $\mathrm{H}$-ficolin, and $\mathrm{M}$-ficolin are examples of soluble pattern recognition molecules, able to bind certain patterns of chemical structures on microorganisms or altered cells in the body. These molecules are found in complexes with MBL-associated serine proteases (MASP-1, MASP-2, or MASP-3) and with MBL-associated proteins (e.g., MAp-44). Binding of MBL/MASP or ficolin/MASP complexes to a fitting pattern activates and regulates inflammation through initiation of the lectin pathway of the complement system $(6,7)$.

Both insufficient and excessive activation of the lectin pathway may be detrimental. Whereas deficiency of some of these components may be clinically irrelevant in healthy individuals due to redundancy of the immune system, an increased susceptibility to secondary infections or complications was shown, e.g., deficiency in MBL or ficolins, in children with cancer or neonates with necrotizing enterocolitis (NEC) (8-10). In contrast, increased levels of innate immunity proteins, possibly in part explained by polymorphisms in the corresponding genes, may contribute to exaggerated inflammatory responses as observed in acute respiratory distress syndrome $(11,12)$.

Data on the lectin pathway of complement activation in critically ill children are scarce. We measured serum levels of different proteins of this pathway on admission in a large cohort of critically ill children $(n=700)$, compared with those in healthy children $(n=130)$, and assessed their association with baseline characteristics and clinical outcomes (new ICU infections, duration of ICU stay, and mortality). We hypothesized that baseline deficiencies in these proteins, i.e., on admission to the ICU, may be associated with more infectious complications and poor outcome. In addition, we investigated the impact of functional polymorphisms on circulating protein levels and outcomes of critical illness. 


\section{RESULTS}

Lectin Pathway Proteins in Serum From Critically III Children and Healthy Controls

In healthy children, MASP-1 and MASP-3 varied with age, with the highest MASP-1 and lowest MASP-3 levels in
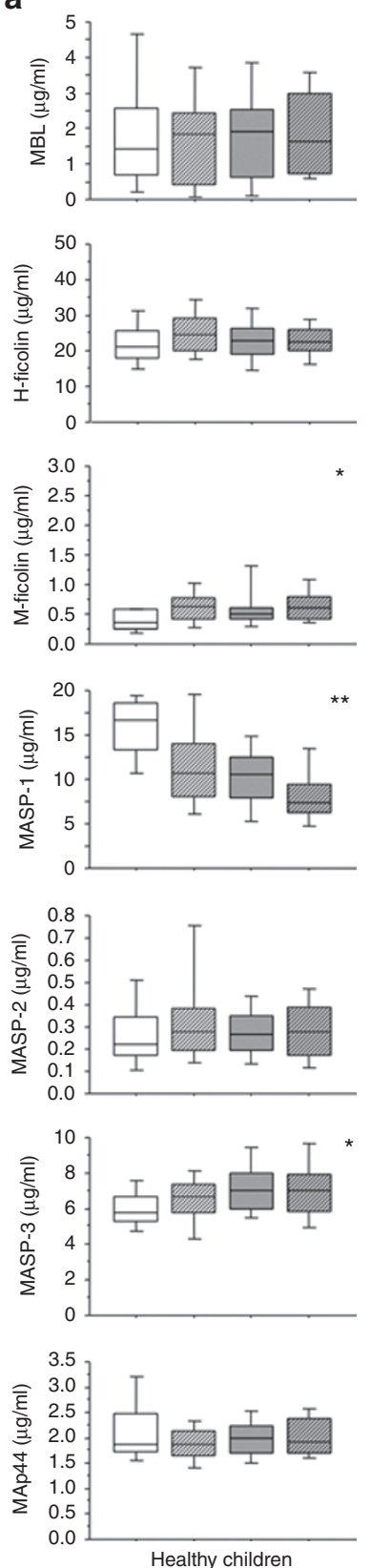

b
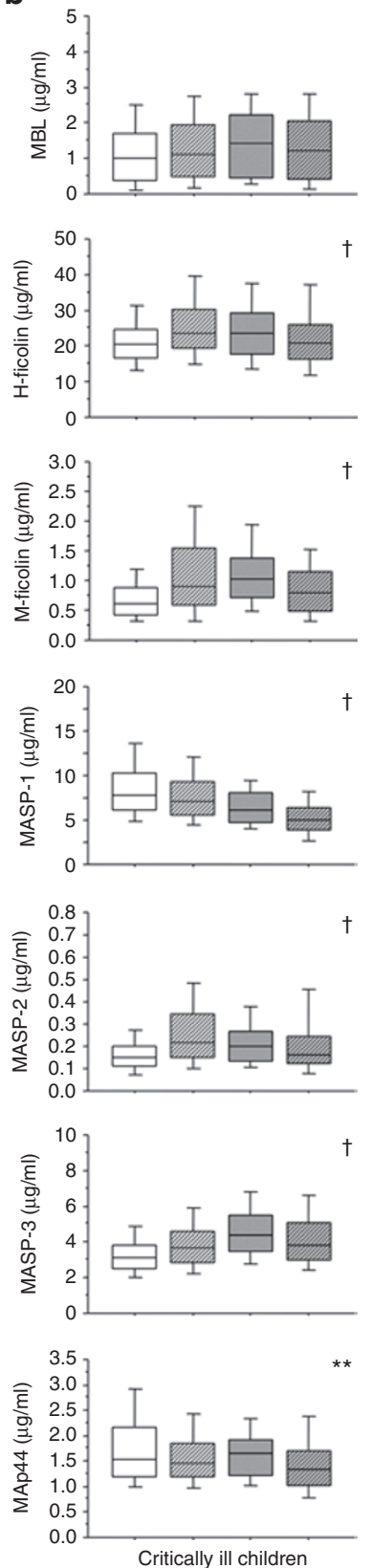

Figure 1. Serum levels of the lectin pathway proteins according to age. (a) Healthy children. (b) Critically ill children. Protein levels were compared among children aged less than 1 y (white boxes, $n=9$ and $n=$ 303 , respectively, for healthy and critically ill children), between 1 and $4 \mathrm{y}$ (hatched white boxes, $n=44$ and $n=166$, respectively), between 4 and 8 y (grey boxes, $n=52$ and $n=89$, respectively), and older than 8 y (hatched grey boxes, $n=25$ and $n=113$, respectively). Data are expressed as box plots, where the central lines indicate the medians, the boxes indicate the interquartile ranges, and the whiskers represent the 10th and 90th percentiles. ${ }^{*} 0.05<P<0.1 ;{ }^{* *} P<0.001 ;{ }^{\dagger} P<0.0001$ in Kruskal-Wallis test. MASP, MBL-associated serine protease; MBL, mannose-binding lectin. children younger than $1 \mathrm{y}$ of age (Figure 1a). Due to the inherent difficulty of recruiting healthy children in this youngest group, there was an imbalance between the age of the critically ill $(1.3(0.3-5.0)$ y) and healthy children (4.6 (2.2-6.8) y; $P<0.0001)$. To avoid bias due to this age difference, we selected two matched cohorts of critically ill children and controls through propensity score matching (Table 1). In the matched population, on-admission levels of MASP-1, MASP-2, MASP-3, and MAp-44 in critically ill patients were significantly lower than the levels in healthy controls (Table 1). Conversely, M-ficolin levels were higher in critically ill patients. MBL and H-ficolin levels were comparable in both groups.

\section{Lectin Pathway Proteins on ICU Admission in Relation to Baseline Characteristics}

In critically ill children, on-admission levels of the proteins increased with age, except for an inverse relation for MASP-1 and MAp-44 (Figure $1 \mathrm{~b}$ and Table 2). A history of malignancy was associated with higher levels of MASP-2 (0.36 (0.17-0.55) vs. $0.17(0.12-0.24) \mu \mathrm{g} / \mathrm{ml} ; P<0.0001)$ and $\mathrm{H}$-ficolin $(26.29$ $(21.75-36.15)$ vs. $21.09(17.05-26.40) \mu \mathrm{g} / \mathrm{ml} ; P=0.0001)$. Patients with diabetes mellitus had lower MBL levels $(0.26$ $(0.02-0.32) \mu \mathrm{g} / \mathrm{ml})$ than those without diabetes $(1.10(0.43-$ $1.94) \mu \mathrm{g} / \mathrm{ml} ; P=0.003)$. Cardiac patients had lower levels of MASP-2 (0.15 (0.11-0.21) vs. $0.24(0.16-0.41) \mu \mathrm{g} / \mathrm{ml} ; P<$ $0.0001)$ and $\mathrm{H}$-ficolin (20.66 (16.60-24.98) vs. 25.70 (19.59$34.85) \mu \mathrm{g} / \mathrm{ml} ; P<0.0001)$ than the other patients. Admission levels of all proteins correlated inversely with severity of illness on ICU admission, as reflected in the Pediatric Risk of Mortality (PRISM) score (Table 2) $(13,14)$.

Table 1. Comparison between propensity score-matched patients and healthy controls

\begin{tabular}{lccc}
\hline & Patients $(n=81)$ & $\begin{array}{c}\text { Healthy controls } \\
(n=81)\end{array}$ & Pvalue \\
\hline $\begin{array}{l}\text { Demographics } \\
\begin{array}{l}\text { Median age } \\
\text { (IQR), y }\end{array}\end{array}$ & $3.3(1.6-4.7)$ & $3.6(1.6-5.3)$ & 0.74 \\
$\begin{array}{l}\text { Male gender, } \\
n(\%)\end{array}$ & $53(65.4)$ & $46(56.8)$ & 0.26 \\
$\begin{array}{l}\text { Mean BMI } \\
\text { (95\% Cl), kg/m² }\end{array}$ & $15.8(15.3-16.3)$ & $16.2(15.7-16.6)$ & 0.21 \\
Median protein levels (IQR), $\mu \mathrm{g} / \mathrm{ml}$ & & \\
MBL & $1.35(0.42-2.19)$ & $1.62(0.58-2.16)$ & 0.53 \\
H-ficolin & $22.03(19.19-28.54)$ & $24.00(20.04-26.84)$ & 0.41 \\
$\begin{array}{l}\text { M-ficolin } \\
\text { MASP-1 }\end{array}$ & $0.91(0.64-1.39)$ & $0.55(0.40-0.72)$ & $<0.0001$ \\
MASP-2 & $6.46(4.79-8.06)$ & $11.23(7.89-13.93)$ & $<0.0001$ \\
MASP-3 & $0.19(0.13-0.27)$ & $0.26(0.19-0.37)$ & 0.001 \\
MAp-44 & $3.73(3.05-4.70)$ & $6.86(5.80-7.71)$ & $<0.0001$ \\
\hline
\end{tabular}

$\mathrm{Cl}$, confidence interval; IQR, interquartile range; MAp, MBL-associated protein; MASP,

MBL-associated serine protease; MBL, mannose-binding lectin. 
Table 2. Association of on-admission levels of the lectin pathway proteins with parameters of disease severity

\begin{tabular}{lcl}
\hline & \multicolumn{2}{c}{ Rho $(P)$} \\
\cline { 2 - 3 } Proteins $(\mu \mathrm{g} / \mathrm{ml})$ & $0.102(0.008)$ & \multicolumn{1}{c}{ PRISM score $^{\mathrm{a}}$} \\
\hline MBL & $0.138(0.0003)$ & $-0.090(0.02)$ \\
H-ficolin & $0.260(<0.0001)$ & $-0.096(0.01)$ \\
M-ficolin & $-0.344(<0.0001)$ & $-0.146(0.0001)$ \\
MASP-1 & $0.226(<0.0001)$ & $-0.249(<0.0001)$ \\
MASP-2 & $0.344(<0.0001)$ & $-0.251(<0.0001)$ \\
MASP-3 & $-0.164(<0.0001)$ & $-0.144(0.0002)$ \\
MAp-44 &
\end{tabular}

MAp, MBL-associated protein; MASP, MBL-associated serine protease; MBL, mannosebinding lectin; PRISM, Pediatric Risk of Mortality.

a Modified PRISM score: PRISM score (13) calculated with only the admission value of blood glucose, which is unaffected by the study intervention. Similar associations were observed with the Risk Adjustment in Congenital Heart Surgery (RACHS) score for patients undergoing cardiac surgery for congenital heart disease, with a higher score indicating a higher risk of death (14).

\section{Association of the Lectin Pathway Proteins on ICU Admission With Outcome}

In a univariate analysis, patients who acquired an infection at any time in ICU had lower on-admission MASP-3 levels than those who did not acquire an infection $(P<0.0001$; Figure 2a). The other proteins were not associated with infection (data not shown). After correcting for baseline characteristics, risk factors, and the other lectin pathway proteins in multivariate logistic regression analysis, low MASP-3 levels remained independently associated with acquisition of infection (Table 3 ). Indeed, the corresponding odds ratio and 95\% confidence interval of 0.809 (0.675-0.959) per $\mu \mathrm{g} /$ $\mathrm{ml}$ MASP-3 added $(P=0.02)$ illustrate a lower risk of infection for a higher on-admission MASP-3 level. Performance of on-admission MASP-3 levels in the prediction of infection (area under the curve of 0.64) was somewhat better than that of C-reactive protein (CRP; area under the curve of 0.58 ; Figure 3). MASP-3 and CRP levels did not correlate (data not shown).

In a univariate analysis, lower on-admission MASP-3 levels were observed in patients needing a prolonged ICU stay (at least $3 \mathrm{~d}$ ) than in patients with a shorter ICU stay $(P$ $<0.0001$; Figure 2b). A similar relation was found between lower levels of on-admission MASP-2 (0.16 (0.11-0.24) vs. 0.18 (0.13-0.27) $\mu \mathrm{g} / \mathrm{ml} ; P=0.002)$ or H-ficolin (20.73 (16.60-25.75) vs. $22.08(18.20-28.77) \mu \mathrm{g} / \mathrm{ml} ; P=0.002)$ and prolonged ICU stay. There was no association between the levels of the other proteins and ICU stay. In multivariate Cox proportional hazard analysis, correcting for baseline risk factors and the other lectin pathway proteins, a low on-admission MASP-3 (but not MASP-2 or H-ficolin) level remained an independent risk factor for prolonged time to ICU discharge (Table 4). The hazard ratio and $95 \%$ confidence interval were 1.088 and 1.020-1.157, respectively $(P=0.01)$, indicating a higher likelihood of earlier alive ICU discharge at any time with a higher on-admission MASP-3 level. The predictive value of MASP-3 for the likelihood of early alive discharge was maintained when acquisition
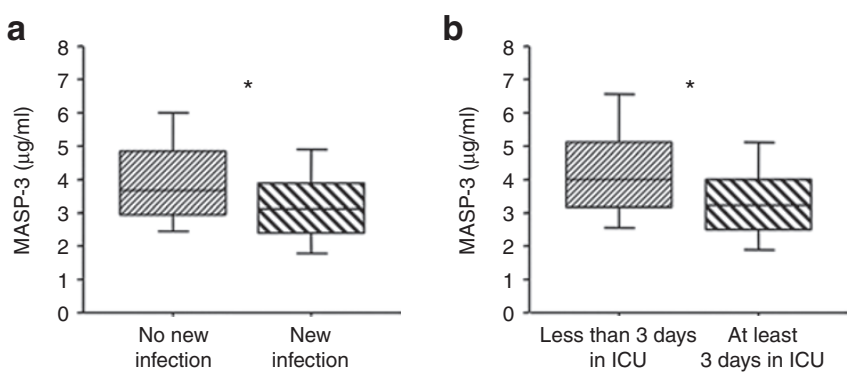

Figure 2. Univariate analysis for MASP-3 levels in relation to risk of new infection and prolonged need of intensive care. (a) Risk of new infection. Of the patients with an on-admission serum sample, 218 acquired a new infection (downward hatched box), whereas 453 did not (upward hatched box). (b) Prolonged need of intensive care. Of the patients with an on-admission serum sample, 375 patients needed intensive care for at least 3 d (downward hatched box), whereas 296 had a shorter ICU stay (upward hatched box). Data are expressed as box plots, where the central lines indicate the medians, the boxes indicate the interquartile ranges, and the whiskers indicate the 10th and 90th percentiles. ${ }^{*} P<0.0001$. ICU, intensive care unit; MASP, mannose-binding lectin-associated serine protease.

Table 3. Multivariate regression analysis for new infection

\begin{tabular}{lcc}
\hline & Odds ratio $(95 \% \mathrm{Cl})^{\mathrm{a}}$ & Pvalue \\
\hline Age (per year added) & $0.896(0.846-0.946)$ & 0.0001 \\
Gender (male) & $1.162(0.786-1.720)$ & 0.45 \\
BMI (per kg/m² added) & $0.990(0.951-1.026)$ & 0.55 \\
Randomized intervention (IIT) & $0.637(0.433-0.934)$ & 0.02 \\
Cardiac surgery & $0.225(0.126-0.397)$ & $<0.0001$ \\
Malignancy & $0.212(0.066-0.608)$ & 0.006 \\
Modified PRISM score & $1.154(1.110-1.203)$ & $<0.0001$ \\
(per unit added) & $1.009(1.004-1.015)$ & 0.0005 \\
CRP $($ per $\mathrm{mg} / \mathrm{l}$ added) & $1.133(0.951-1.352)$ & 0.16 \\
MBL (per $\mu \mathrm{g} / \mathrm{ml}$ added) & $1.006(0.977-1.037)$ & 0.68 \\
H-ficolin $($ per $\mu \mathrm{g} / \mathrm{ml}$ added) & $1.095(0.969-1.388)$ & 0.36 \\
M-ficolin $($ per $\mu \mathrm{g} / \mathrm{ml}$ added) & $0.978(0.910-1.049)$ & 0.54 \\
MASP-1 (per $\mu \mathrm{g} / \mathrm{ml}$ added) & $1.006(0.187-5.359)$ & 0.99 \\
MASP-2 (per $\mu \mathrm{g} / \mathrm{ml}$ added) & $0.809(0.675-0.959)$ & 0.02 \\
MASP-3 (per $\mu \mathrm{g} / \mathrm{ml}$ added) & $1.258(0.962-1.663)$ & 0.10 \\
MAp-44 (per $\mu \mathrm{g} / \mathrm{ml}$ added) & & \\
\hline
\end{tabular}

$\mathrm{Cl}$, confidence interval; CRP, C-reactive protein; ICU, intensive care unit; IIT, intensive insulin therapy; MAp, MBL-associated protein; MASP, MBL-associated serine protease; MBL, mannose-binding lectin; PRISM, Pediatric Risk of Mortality.

${ }^{a}$ An odds ratio $>1$ indicates an increased risk of infection. Hence, patients with a higher level of MASP-3 on ICU admission have a lower risk of acquiring a new infection in ICU.

of a new infection was added to the model (hazard ratio: 1.080 (1.009-1.152); $P=0.03)$. The corresponding hazard ratio for infection was $0.238(0.191-0.296 ; P<0.0001)$. There was no association between the levels of any of the proteins measured on ICU admission and ICU mortality (data not shown).

\section{Association of Genetic Polymorphisms in the MASP1 Gene With Protein Levels and Outcomes of Critical Illness}

Because only MASP-3 levels were related to outcomes, we studied only single-nucleotide polymorphisms (SNPs) in 

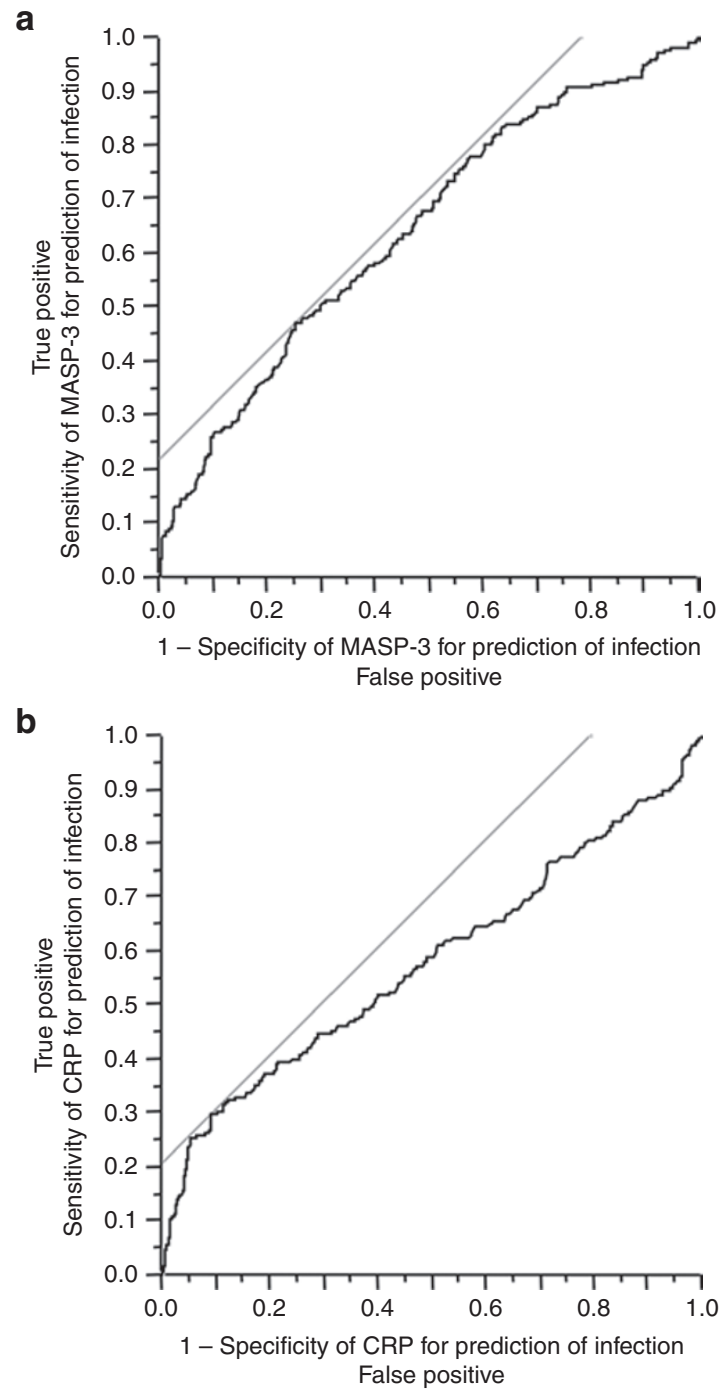

Figure 3. Receiver operating characteristic (ROC) curves for prediction of infection with on-admission MASP-3 and CRP levels. (a) ROC curve for MASP-3: $A \cup C=0.64$. (b) ROC curve for CRP: $A U C=0.58$. Black lines show the ROC curves. The point of intersection between the black and the grey lines shows the cutoffs for on-admission MASP-3 and CRP levels, respectively, with the best combined specificity and sensitivity for prediction of infection. AUC, area under the curve; CRP, C-reactive protein; MASP, mannose-binding lectin-associated serine protease.

the MASP1 gene, encoding MASP-1, MASP-3, and MAp-44. For all SNPs, allele frequencies showed a similar distribution in patients and controls (Table 5) and were consistent with Hardy-Weinberg equilibrium. However, for five SNPs, more than $5 \%$ of the samples could not be attributed to a genotype. Of the remaining SNPs, 18 were monomorphic or near monomorphic, with less than $1 \%$ attributed to a genotype different from the ancestral allele homozygosity. These 23 SNPs were not further considered.

In univariate analysis, only rs710469 (C>T, intron SNP) and rs850312 (G>A, synonymous SNP in coding region) were associated with MASP-3 levels. More specifically, rs710469 variant allele $(\mathrm{T})$ homozygosity and presence of a variant allele (A) in rs850312 were associated with higher MASP-3
Table 4. Cox proportional hazard analysis for likelihood of early alive discharge from ICU

\begin{tabular}{|c|c|c|}
\hline & Hazard ratio $(95 \% \mathrm{Cl})^{\mathrm{a}}$ & $P$ value \\
\hline Age (per year added) & $1.039(1.017-1.061)$ & 0.0005 \\
\hline Gender (male) & $0.939(0.799-1.104)$ & 0.45 \\
\hline BMI (per kg/m² added) & $0.999(0.973-1.018)$ & 0.90 \\
\hline Randomized intervention (IIT) & $1.201(1.022-1.412)$ & 0.03 \\
\hline Cardiac surgery & $1.917(1.498-2.473)$ & $<0.0001$ \\
\hline Malignancy & $1.007(0.644-1.512)$ & 0.97 \\
\hline Modified PRISM score (per unit added) & $0.915(0.899-0.932)$ & $<0.0001$ \\
\hline CRP (per mg/l added) & $0.999(0.997-1.001)$ & 0.29 \\
\hline MBL (per $\mu \mathrm{g} / \mathrm{ml}$ added) & $1.037(0.960-1.118)$ & 0.36 \\
\hline $\mathrm{H}$-ficolin (per $\mu \mathrm{g} / \mathrm{ml}$ added) & $1.001(0.990-1.012)$ & 0.82 \\
\hline M-ficolin (per $\mu \mathrm{g} / \mathrm{ml}$ added) & $1.010(0.950-1.049)$ & 0.71 \\
\hline MASP-1 (per $\mu \mathrm{g} / \mathrm{ml}$ added) & $0.994(0.965-1.023)$ & 0.70 \\
\hline MASP-2 (per $\mu \mathrm{g} / \mathrm{ml}$ added) & $0.992(0.498-1.890)$ & 0.98 \\
\hline MASP-3 (per $\mu \mathrm{g} / \mathrm{ml}$ added) & $1.088(1.020-1.157)$ & 0.01 \\
\hline MAp-44 (per $\mu \mathrm{g} / \mathrm{ml}$ added) & $0.937(0.822-1.059)$ & 0.30 \\
\hline \multicolumn{3}{|c|}{$\begin{array}{l}\mathrm{Cl} \text {, confidence interval; CRP, C-reactive protein; ICU, intensive care unit; IIT, intensive } \\
\text { insulin therapy; MAp, MBL-associated protein; MASP, MBL-associated serine protease; } \\
\text { MBL, mannose-binding lectin; PRISM, Pediatric Risk of Mortality. }\end{array}$} \\
\hline \multicolumn{3}{|c|}{$\begin{array}{l}\text { aA hazard ratio }>1 \text { indicates a higher likelihood of earlier alive discharge from the ICU at } \\
\text { any time. Hence, higher on-admission MASP-3 levels decrease the risk of an extended } \\
\text { stay in the ICU. }\end{array}$} \\
\hline
\end{tabular}

levels (Figure 4a,b). Taking into account the relationship between higher MASP-3 and better outcome, we considered the rs710469 TT and rs850312 AA or AG genotypes as "protective." Combining the two SNPs as one endpoint, patients having maximally one protective genotype had lower MASP-3 levels than patients having both protective genotypes (Figure 4c). Similarly, patients without any protective SNP had lower MASP-3 levels than patients having at least one protective SNP (Figure 4d). In multiple linear regression analysis using age, PRISM score, and genotype, having an ancestral allele in rs710469 (CC or CT) or homozygosity in the ancestral allele for rs850312 (GG)-i.e., having maximally one protective SNPdetermined low MASP-3 levels, independent of-and without any significant interaction with-younger age and higher severity of illness (Table 6). Similar results were obtained for patients having no protective SNP (data not shown). rs710469 and rs850312 were not associated with the acquisition of infection or time in ICU in univariate or multivariate analysis with or without the MASP protein levels present in the model.

\section{DISCUSSION}

Critically ill children with varying underlying pathology show altered serum profiles of several lectin pathway proteins, with low MASP and high M-ficolin levels, on ICU admission compared with healthy children. Low MASP-3 levels, in particular, were robustly associated with a higher risk of acquiring a new infection in the ICU and prolonged need for intensive care. Age, severity of illness, and genetic variation in the MASP1 gene independently explained the variation in MASP-3 levels 
Table 5. Distribution of the SNPs in critically ill and healthy children

\begin{tabular}{|c|c|c|c|c|}
\hline $\begin{array}{l}\text { SNPs in MASP-1/ } \\
\text { MASP-3 }\end{array}$ & Genotype & $\begin{array}{c}\text { Critically ill } \\
\text { children, } n(\%)\end{array}$ & $\begin{array}{c}\text { Healthy } \\
\text { children, } n(\%)\end{array}$ & $P$ value \\
\hline \multirow{3}{*}{$\begin{array}{l}r s 3105782 \\
T>C\end{array}$} & $\mathrm{CC}$ & $42(6.9)$ & $12(9.4)$ & \multirow[t]{3}{*}{0.36} \\
\hline & $\mathrm{CT}$ & $232(38.0)$ & $54(42.2)$ & \\
\hline & TT & $322(52.8)$ & $60(46.9)$ & \\
\hline \multirow{2}{*}{$\begin{array}{l}\mathrm{rs} 113938200 \\
\mathrm{C}>\mathrm{T}^{\mathrm{a}}\end{array}$} & $\mathrm{CC}$ & 595 (97.5) & $127(99.2)$ & \multirow[t]{2}{*}{0.95} \\
\hline & $\mathrm{CT}$ & $5(0.8)$ & $1(0.8)$ & \\
\hline \multirow[t]{3}{*}{ rs710469C>T } & $\mathrm{CC}$ & $169(27.7)$ & $34(26.6)$ & \multirow[t]{3}{*}{0.86} \\
\hline & $\mathrm{CT}$ & $294(48.2)$ & $66(51.6)$ & \\
\hline & TT & $134(22.0)$ & $27(21.1)$ & \\
\hline \multirow[t]{3}{*}{ rs874603 A>G } & $A A$ & $502(82.3)$ & $106(82.8)$ & \multirow[t]{3}{*}{0.96} \\
\hline & AG & 91 (14.9) & $20(15.6)$ & \\
\hline & GG & $6(1.0)$ & $1(0.8)$ & \\
\hline \multirow[t]{2}{*}{$\mathrm{rs} 710456 \mathrm{~T}>\mathrm{C}^{\mathrm{a}}$} & $\mathrm{CT}$ & $2(0.3)$ & $0(0.0)$ & \multirow[t]{2}{*}{0.51} \\
\hline & $\mathrm{TT}$ & $598(98.0)$ & $128(100)$ & \\
\hline \multirow{3}{*}{$\begin{array}{l}\text { rs3774268 } \\
G>A\end{array}$} & $A A$ & $12(2.0)$ & $3(2.3)$ & \multirow[t]{3}{*}{0.90} \\
\hline & AG & $148(24.3)$ & $30(23.4)$ & \\
\hline & GG & 419 (68.7) & 93 (72.7) & \\
\hline $\begin{array}{l}\text { rs6799834 } \\
C>T^{a, b}\end{array}$ & $\mathrm{CC}$ & $562(92.1)$ & $116(90.6)$ & 0.99 \\
\hline \multirow{2}{*}{$\begin{array}{l}\text { rs16861801 } \\
G>C^{a, b}\end{array}$} & CG & $10(1.6)$ & $0(0.0)$ & \multirow[t]{2}{*}{0.13} \\
\hline & GG & 518 (84.9) & $121(94.5)$ & \\
\hline \multirow{2}{*}{$\begin{array}{l}\mathrm{rs} 35384947 \\
\mathrm{G}>\mathrm{A}^{\mathrm{a}}\end{array}$} & AG & $1(0.2)$ & $0(0.0)$ & \multirow[t]{2}{*}{0.64} \\
\hline & GG & 595 (97.5) & $127(99.2)$ & \\
\hline \multirow{2}{*}{$\begin{array}{l}\text { rs } 28945068 \\
G>A\end{array}$} & AG & $14(2.3)$ & $5(3.9)$ & \multirow[t]{2}{*}{0.30} \\
\hline & GG & 591 (96.9) & $123(96.1)$ & \\
\hline \multirow{2}{*}{$\begin{array}{l}r s 28945071 \\
A>G^{a}\end{array}$} & $\mathrm{AA}$ & $597(97.9)$ & $127(99.2)$ & \multirow[t]{2}{*}{0.30} \\
\hline & AG & $5(0.8)$ & $0(0.0)$ & \\
\hline \multirow{2}{*}{$\begin{array}{l}\text { rs } 28945069 \\
C>T\end{array}$} & CC & 602 (98.7) & $126(98.4)$ & \multirow[t]{2}{*}{0.26} \\
\hline & $\mathrm{CT}$ & $6(1.0)$ & $0(0.0)$ & \\
\hline $\begin{array}{l}\text { rs115022399 } \\
C>A^{a}\end{array}$ & $\mathrm{CC}$ & $601(98.5)$ & $127(99.2)$ & 0.99 \\
\hline \multirow[t]{3}{*}{ rs850312G>A } & AA & $56(9.2)$ & $17(13.3)$ & \multirow[t]{3}{*}{0.37} \\
\hline & AG & $276(45.2)$ & $54(42.2)$ & \\
\hline & GG & $259(42.5)$ & $54(42.2)$ & \\
\hline \multirow{2}{*}{$\begin{array}{l}\text { rs115961221 } \\
G>A\end{array}$} & AG & $31(5.1)$ & $5(3.9)$ & 0.58 \\
\hline & GG & $566(92.8)$ & $120(93.8)$ & \\
\hline rs7652842 & $A A$ & $594(97.4)$ & $121(94.5)$ & 0.23 \\
\hline$A>G$ & AG & $13(2.1)$ & $5(3.9)$ & \\
\hline $\begin{array}{l}\mathrm{rs} 111908734 \\
\mathrm{G}>\mathrm{T}^{\mathrm{a}}\end{array}$ & GG & 603 (98.9) & $127(99.2)$ & 0.99 \\
\hline $\begin{array}{l}\text { rs116384821 } \\
C>A^{a}\end{array}$ & $\mathrm{CC}$ & $599(98.2)$ & $127(99.2)$ & 0.99 \\
\hline $\begin{array}{l}\mathrm{rs} 72549155 \\
\mathrm{C}>\mathrm{G}^{\mathrm{a}}\end{array}$ & $\mathrm{CC}$ & $605(99.2)$ & $127(99.2)$ & 0.99 \\
\hline rs73068950 & $\mathrm{CC}$ & 602 (98.7) & $126(98.4)$ & 0.43 \\
\hline$C>T^{a}$ & $\mathrm{CT}$ & $3(0.5)$ & $0(0.0)$ & \\
\hline rs114365879 & $\mathrm{CC}$ & 603 (98.9) & $127(99.2)$ & 0.52 \\
\hline $\mathrm{C}>\mathrm{T}^{\mathrm{a}}$ & $\mathrm{CT}$ & $2(0.3)$ & $0(0.0)$ & \\
\hline
\end{tabular}

Table 5. Continued

\begin{tabular}{|c|c|c|c|c|}
\hline $\begin{array}{l}\text { SNPs in MASP-1/ } \\
\text { MASP-3 }\end{array}$ & Genotype & $\begin{array}{c}\text { Critically ill } \\
\text { children, } n(\%)\end{array}$ & $\begin{array}{c}\text { Healthy } \\
\text { children, } n(\%)\end{array}$ & $P$ value \\
\hline \multirow{2}{*}{$\begin{array}{l}\mathrm{rs} 116763673 \\
\mathrm{C}>\mathrm{T}^{\mathrm{a}}\end{array}$} & $\mathrm{CC}$ & 603 (98.9) & $127(99.2)$ & \multirow[t]{2}{*}{0.64} \\
\hline & $\mathrm{CT}$ & $1(0.2)$ & $0(0.0)$ & \\
\hline \multirow{2}{*}{$\begin{array}{l}\text { rs116595107 } \\
C>T^{a, b}\end{array}$} & $\mathrm{CC}$ & $526(86.2)$ & $118(92.2)$ & \multirow[t]{2}{*}{0.92} \\
\hline & $\mathrm{CT}$ & $5(0.8)$ & $1(0.8)$ & \\
\hline \multirow{2}{*}{$\begin{array}{l}\text { rs73886128 } \\
\text { C> } T^{a}\end{array}$} & $\mathrm{CC}$ & 603 (98.9) & $126(98.4)$ & \multirow[t]{2}{*}{0.43} \\
\hline & $\mathrm{CT}$ & $3(0.5)$ & $0(0.0)$ & \\
\hline \multirow{2}{*}{$\begin{array}{l}\mathrm{rs} 116001173 \\
\mathrm{C}>\mathrm{T}^{\mathrm{a}}\end{array}$} & $\mathrm{CC}$ & $600(98.4)$ & $127(99.2)$ & \multirow[t]{2}{*}{0.65} \\
\hline & $\mathrm{CT}$ & $1(0.2)$ & $0(0.0)$ & \\
\hline $\begin{array}{l}\mathrm{rs} 115241263 \\
\mathrm{C}>\mathrm{T}^{\mathrm{a}}\end{array}$ & CC & $593(97.2)$ & $126(98.4)$ & 0.99 \\
\hline $\begin{array}{l}\text { rs78137557 } \\
A>G^{a}\end{array}$ & $\mathrm{AA}$ & $592(97.0)$ & $126(98.4)$ & 0.99 \\
\hline $\begin{array}{l}r s 72549252 \\
T>C^{a}\end{array}$ & $\mathrm{TT}$ & $606(99.3)$ & $127(99.2)$ & 0.99 \\
\hline $\begin{array}{l}\text { rs115647447 } \\
G>A^{a}\end{array}$ & GG & $602(98.7)$ & $127(99.2)$ & 0.99 \\
\hline $\begin{array}{l}\mathrm{rs} 74784100 \\
\mathrm{C}>\mathrm{T}^{\mathrm{a}}\end{array}$ & $\mathrm{CC}$ & $604(99.0)$ & $127(99.2)$ & 0.99 \\
\hline \multirow{2}{*}{$\begin{array}{l}\text { rs77189011 } \\
\mathrm{C}>\mathrm{T}^{\mathrm{b}}\end{array}$} & $\mathrm{CC}$ & $523(85.7)$ & $110(85.9)$ & \multirow[t]{2}{*}{0.10} \\
\hline & $\mathrm{CT}$ & $7(1.1)$ & $4(3.1)$ & \\
\hline \multirow{2}{*}{$\begin{array}{l}\mathrm{rs} 1062049 \\
\mathrm{C}>\mathrm{T}^{\mathrm{a}, \mathrm{b}}\end{array}$} & $\mathrm{CC}$ & $589(96.6)$ & $119(93.0)$ & \multirow[t]{2}{*}{0.37} \\
\hline & $\mathrm{CT}$ & $4(0.7)$ & $0(0.0)$ & \\
\hline
\end{tabular}

MASP, mannose-binding lectin-associated serine protease; SNP, single-nucleotide polymorphism

No blood cell sample was available for DNA extraction from 2 healthy children and 90 critically ill patients. For three other patients, the DNA yield was too low for use on the Open Array platform. The percentages of the genotypes are thus calculated relative to 610 critically ill and 128 healthy children. Other missing SNPs could not be reliably attributed to a specific genotype.

aSNPs not further considered for reason of being monomorphic or near monomorphic, with less than $1 \%$ attributed to a genotype different from homozygosity for the

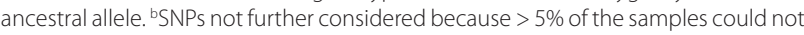
be attributed to a certain genotype.

on ICU admission. However, genetic variation did not by itself contribute to the risk of infection and prolonged critical illness.

Critically ill children showed lower levels of MASP-1, MASP2, MASP-3, and MAp-44 and higher M-ficolin levels on ICU admission than age-matched healthy children, whereas levels of MBL and $\mathrm{H}$-ficolin were comparable. Thus, critical illness has an acute effect on most of these proteins. Matching for age appeared crucial because of the important changes with age reported for most of these proteins $(10,15-18)$ and largely confirmed in our cohorts of healthy and critically ill children.

We observed higher levels of MASP-2 and H-ficolin in critically ill patients with a history of malignancy than in those without. Elevated levels of MASP-2 and MBL, but not of M-ficolin, have been reported for children with cancer $(19,20)$. Low levels of MASP-2 and $\mathrm{H}$-ficolin have been associated with fever, neutropenia, bacteremia, prolonged hospitalization, and intravenous antimicrobial therapy $(9,21)$. Data on the lectin pathway in pediatric critical illness are scarce and available only for small cohorts of neonates. Low MBL and high M-ficolin levels in umbilical cord blood have been associated 
a

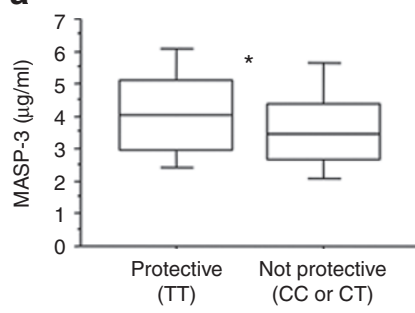

C

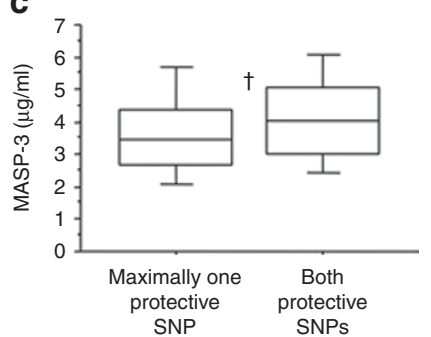

b

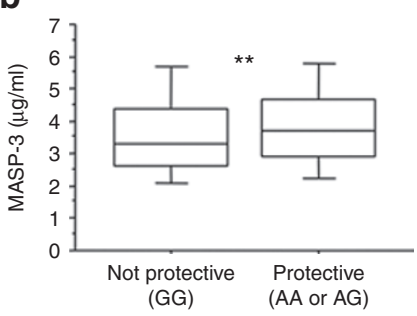

d

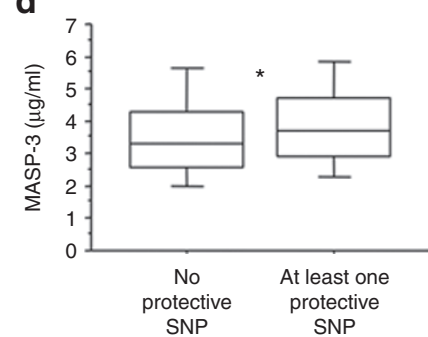

Figure 4. Impact of genetic variation on the on-admission MASP-3 levels. Data are expressed as box plots, where the central lines indicate the medians, the boxes indicate the interquartile ranges, and the whiskers indicate the 10th and 90th percentiles. (a) rs710469 protective single-nucleotide polymorphism (SNP) ( $n=131)$ vs. no protective SNP ( $n=446)$, (b) rs850312 protective SNP $(n=246)$ vs. no protective SNP $(n=324)$, (c) rs710469/ rs 850312 maximally one protective SNP $(n=459)$ vs. both protective SNPs $(n=101)$, and (d) rs710469/rs850312 no protective SNP $(n=219)$ vs. at least one protective SNP $(n=341) .{ }^{*} P=0.0003 ;{ }^{* *} P=0.004 ;{ }^{\dagger} P=0.001$. MASP, mannose-binding lectin-associated serine protease.

Table 6. Multiple linear regression analysis for factors determining MASP-3 levels

\begin{tabular}{lccc}
\hline & $\begin{array}{c}\beta \text { coefficient } \\
(95 \% \mathrm{Cl})\end{array}$ & Standardized $\beta$ & $P$ value \\
\hline Age $(/ \mathrm{y})$ & 0.053 & 0.153 & 0.004 \\
& $(0.017-0.090)$ & & \\
$\begin{array}{l}\text { PRISM score } \\
\text { (/unit) }\end{array}$ & -0.070 & -0.227 & $<0.0001$ \\
$\begin{array}{l}\text { Low-MASP-3 } \\
\text { genotype }\end{array}$ & -0.099 to -0.042$)$ & & \\
Interactions & -0.249 & -0.119 & 0.003 \\
$\quad \begin{array}{l}\text { Age } \times \\
\text { low-MASP-3 }\end{array}$ & $(-0.011$ to -0.087$)$ & & \\
genotype & & & \\
$\begin{array}{l}\text { PRISM score } \times \\
\text { low-MASP-3 } \\
\text { genotype }\end{array}$ & $(-0.028$ to 0.069) & 0.094 & \\
\hline
\end{tabular}

Cl, confidence interval; MASP, mannose-binding lectin-associated serine protease; PRISM, Pediatric Risk of Mortality.

aModified PRISM score: PRISM score calculated with only the admission value of blood

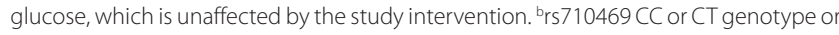
rs850312 GG genotype.

with Gram-negative and early-onset sepsis, and low H-ficolin levels have been associated with susceptibility to Gram-positive and late-onset sepsis $(22,23)$. Low MBL levels in blood from neonates were related to an increased risk of neonatal sepsis and pneumonia $(24,25)$. Cord blood MASP-2 levels tended to be higher for babies with infections (26) and were higher for neonates who developed NEC (17). Risk of death and need for

mechanical ventilation for neonates with NEC were higher when M-ficolin levels were low (10). Major surgery was shown to lead to an initial decrease in MASP-1, MASP-3, and MAp44 levels, followed by gradual recovery $(15,16)$.

In our cohort of critically ill children, low on-admission MASP-3 levels were robustly associated with an increased risk of acquiring a new infection, even after correcting for baseline characteristics, risk factors, and the other lectin pathway proteins. The likelihood for an earlier alive discharge from ICU was also much lower for patients with low on-admission levels of MASP-3 in multivariate analysis. The latter association was only partially attributable to the higher infection rate in these patients because the effect of MASP-3 was somewhat attenuated but remained significant when acquisition of a new infection was added to the statistical model. The biological activity of MASP-3 remains incompletely understood. Recombinant MASP-3 has some activity on insulin-like growth factor-binding protein-5 and some synthetic substrates (27). A critical role of MASP-3 in insulin-like growth factor-binding protein-5 availability during craniofacial, muscle, and neural crest development was suggested based on specific mutations (28-30). In mice, MASP-1 and MASP-3 play a role in the alternative pathway of complement activation and thus might act as a backup system when the lectin pathway is deficient (31). However, the alternative complement activation pathway functioned normally in a patient deficient in MASP-1 and MASP-3 due to a nonsense mutation in the common part of the MASP1 gene (32). Our findings suggest that MASP-3 plays an important role in the host defense against infections in the ICU and may also be of much broader importance as low MASP-3 was associated with prolonged need for intensive care irrespective of infection.

We observed an inverse correlation between on-admission MASP-3 levels and severity of illness, suggesting a more severe acute depression of MASP-3 for sicker patients. Interest in the functional consequences of genetic variation in determining susceptibility and response to disease is increasing, also in critical illness $(3,4,33,34)$. Our study of several SNPs spread throughout the MASP1 gene encoding MASP-3 $(7,35)$ identified two SNPs for which the variant allele was associated with higher on-admission MASP-3 levels. These "protective" genotypes were equally distributed among patients and controls; thus, not having a protective genotype did not predispose to critical illness. Carrying one protective SNP variant appeared sufficient for having higher MASP-3 levels because having both the protective SNPs was not more protective than having only one. The variation in MASP-3 levels was only partially explained by this genetic variation because age and illness severity were additional independent determinants of these protein levels, without interaction with genetic variation. The actual protein level of MASP-3 appeared more important for outcome than genetic variation in the MASP1 gene. Indeed, whereas low on-admission protein levels were clearly associated with risk of infection and prolonged ICU stay, carrying a protective 
SNP variant obviously was not sufficient to compensate for the impact of the acute insult of critical illness that reduces MASP-3 levels and was not associated with risk of infection or ICU stay.

The major strength of our unique study is that it evaluated a wide array of lectin pathway proteins in large cohorts of healthy children and critically ill children with varying underlying pathology and of all ages, in addition to combining this with genetic analyses. However, a first limitation of our study is that although we found robust associations between onadmission MASP-3 levels and clinical outcomes, our study does not provide hard evidence for causal involvement. This would require artificial interference with MASP-3 levels in a randomized study. A second limitation relates to the number of SNPs analyzed. The selected SNPs covered exons, introns, and the $5^{\prime}$ - and $3^{\prime}$-untranslated regions of the MASP1 gene. Nevertheless, we did not study all genetic variations in the MASP1 gene, and hence, we cannot exclude the importance of any other SNPs for the outcome of critically ill children. Moreover, several SNPs did not show any, or showed insufficient, variation in our cohorts, hampering the study of any relation with outcome.

In conclusion, in a large unselected heterogeneous cohort of critically ill children, we observed remarkable disturbances in several proteins of the lectin pathway of complement activation on ICU admission. We identified a low circulating MASP-3 protein level as an independent predictor of subsequent acquisition of infection and prolonged dependency on intensive care. The impact of critical illness appeared to overwhelm any impact of protective SNPs on MASP-3 protein levels. These intriguing results open the way for further investigation of the role of MASP-3 in general and in critical illness in particular. Obviously, additional pathophysiological research will be needed to further elucidate the role of the lectin pathway of complement activation during critical illness.

Table 7. Characteristics of the critically ill patients and healthy volunteers

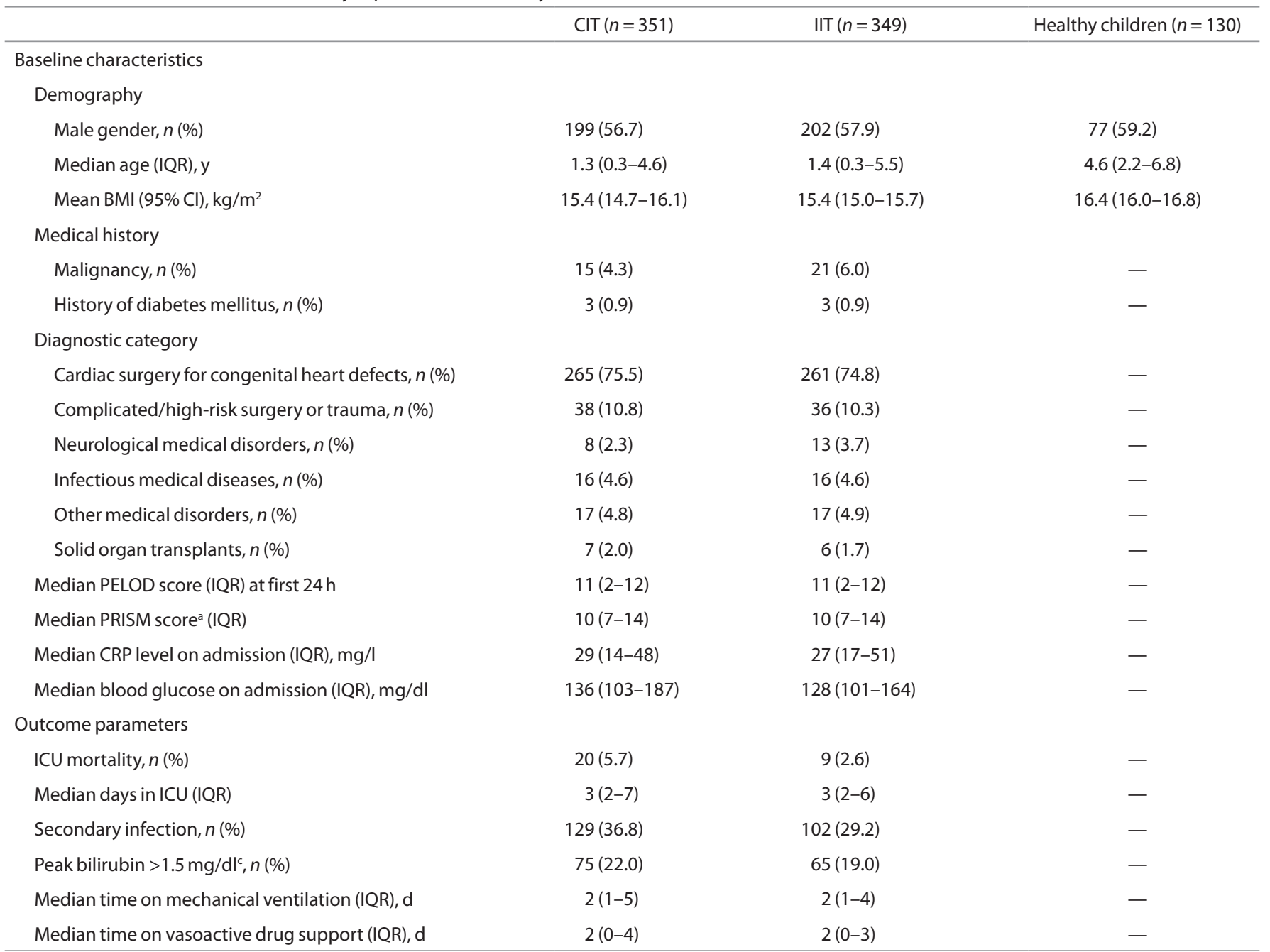

$\mathrm{Cl}$, confidence interval; CIT, conventional insulin therapy; CRP, C-reactive protein; ICU, intensive care unit; IQR, interquartile range; IIT, intensive insulin therapy; PELOD, Pediatric Logistic Organ Dysfunction; PRISM, Pediatric Risk of Mortality.

aModified Pediatric Risk of Mortality score: PRISM score calculated with only the admission value of blood glucose, which is unaffected by the study intervention. ${ }^{\circ}$ To convert glucose to $\mathrm{mmol} / \mathrm{l}$, multiply by 0.05551 . To convert bilirubin to $\mu \mathrm{mol} / \mathrm{l}$, multiply by 17.1 . 


\section{METHODS}

Subjects

This is a preplanned analysis of all patients $(n=700)$ included in a randomized controlled study on tight glycemic control in the pediatric ICU (1). Patients had been allocated to conventional insulin therapy $(n=351$, insulin started only when blood glucose exceeded $215 \mathrm{mg} / \mathrm{dl}$, and the dose was tapered down and stopped when glycemia decreased to levels less than $180 \mathrm{mg} / \mathrm{dl}$ ) or intensive insulin therapy ( $n=349$, insulin infused to achieve age-adjusted normal fasting glucose levels). Patient characteristics were comparable for both randomization groups (Table 7). Intensive insulin therapy reduced nosocomial infections, ICU stay, and ICU mortality (1). As controls, we included 130 healthy children (Table 7) scheduled for minor ambulatory surgery, allowing preoperative blood withdrawal after catheterization required for induction and/or maintenance of anesthesia. The study was approved by the KU Leuven Institutional Review Board (ML2586 and amendment) and was registered with ClinicalTrials.gov (NCT00214916). The study was performed in accordance with the 1964 Declaration of Helsinki and its amendments. Written informed consent was obtained from the parents or legal guardians of patients and controls.

\section{Biochemical and Genetic Analyses}

$\mathrm{CRP}$ was determined by routine clinical chemistry. Whole arterial blood glucose was measured at 1 - to 4 -h intervals using the ABL700 blood gas analyzer (Radiometer Medical A/S, Copenhagen, Denmark). On ICU admission, serum and blood cell samples for DNA extraction were collected and stored at $-80{ }^{\circ} \mathrm{C}$ until analysis. For 29 and 90 patients, no baseline serum or blood cell sample was available, respectively.

Table 8. The SNPs determined in the patients and healthy children

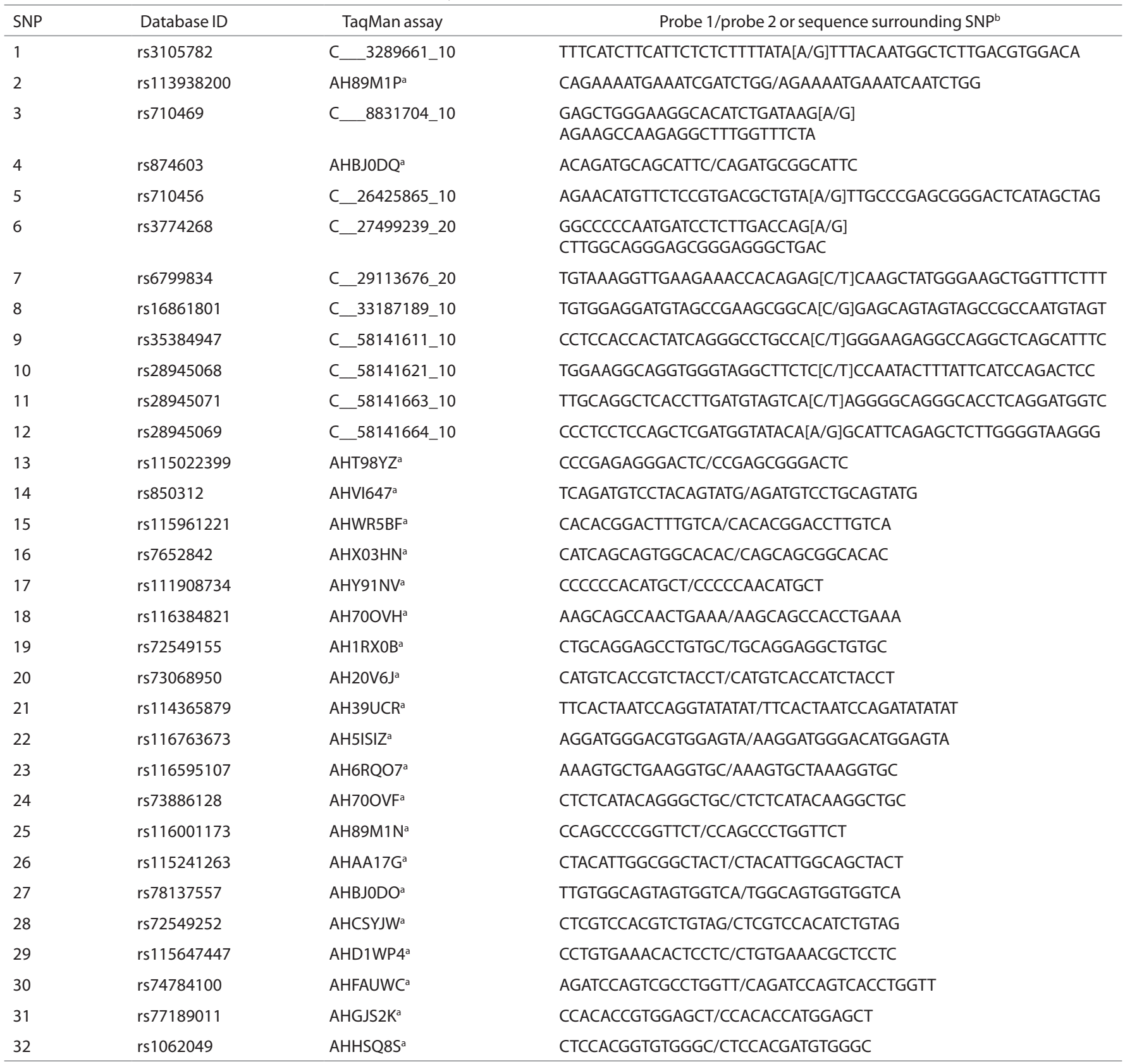

SNP, single-nucleotide polymorphism.

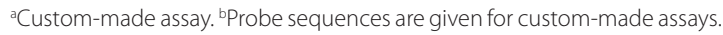


Serum levels of MBL, H-ficolin, M-ficolin, MASP-2, MASP-3, and MAp-44 were measured by sandwich-type antibody-based time-resolved immunofluorometric assays (TRIFMAs) (15,36-38). MASP-1 was measured using an inhibition-type TRIFMA (16).

Genetic analyses were prospectively planned as a target gene approach, focused on SNPs in genes encoding proteins associated with outcome. Thus, 32 SNPs in the MASP1 gene were selected (Table 8), based on frequencies in the SNP database and location (covering exons, introns, and the $5^{\prime}$ - and $3^{\prime}$-untranslated regions). The MASP1 gene encodes a transcript that may be spliced to form mRNAs encoding the three proteins MASP-1, MASP-3, and MAp-44. MASP-1 and MASP-3 share five structural domains but differ by having two different serine protease domains (28). MAp-44 shares the first four structural domains with MASP- 1 and MASP-3 but has in addition a unique 17 amino acid C-terminal end. We thus analyzed SNPs in the areas encoding shared domains (included in exons 1-8, 10, and 11; exon 9 encodes the MAp-44-specific sequence) and in the area of the gene encoding the MASP-3-specific protease domains (exon 12).

DNA was extracted from the blood cells using the QIAsymphony robot and the corresponding DNA extraction kit (QIAGEN, Venlo, The Netherlands). Samples and negative controls without DNA template were analyzed by the high-throughput TaqMan Open Array Genotyping Platform according to the manufacturer's protocol (ABI, Foster City, CA). First, samples were diluted to a final concentration of $\sim 50 \mathrm{ng} \mathrm{DNA} / \mu \mathrm{l}$ in 96 -well plates. Negative controls were randomly distributed on all 96-well plates to estimate the quality of the samples. Subsequently, 384-well plates were prepared using a Biomek NX (Beckman Coulter, Fullerton, CA). Finally, $100 \mathrm{ng}$ of DNA was mixed with $2 \mu \mathrm{l}$ TaqMan Open Array Mastermix (ABI) in 384-well plates, and the samples were loaded with the Open Array NT Autoloader (ABI) onto custom-designed 32-SNP Open Array plates (ABI), containing the TaqMan assays described in Table 8. PCR was performed using a GeneAmp 9700 thermal cycler (ABI) according to the following conditions: $91{ }^{\circ} \mathrm{C}$ for $10 \mathrm{~min}+50$ cycles $\left(51^{\circ} \mathrm{C}\right.$ for $23 \mathrm{~s} ; 53.5^{\circ} \mathrm{C}$ for $30 \mathrm{~s}$; $54.5^{\circ} \mathrm{C}$ for $13 \mathrm{~s} ; 97^{\circ} \mathrm{C}$ for $22 \mathrm{~s}$; and $92{ }^{\circ} \mathrm{C}$ for $\left.7 \mathrm{~s}\right)+20^{\circ} \mathrm{C}$ for $5 \mathrm{~min}$, followed by storage at $4{ }^{\circ} \mathrm{C}$ until analysis. Fluorescence of the FAM and VIC reporters was read with the Open Array NT Imager (ABI). Data were analyzed with the Biotrove Open Array SNP Genotyping Analysis Software package, version 1.0.3 (Biotrove, Woburn, MA).

\section{Statistical Analysis}

Data were analyzed with JMP10 (SAS Institute, Cary, NC). Two-sided $P$ values less than 0.05 were considered significant. Data are presented as mean (95\% confidence interval), median (interquartile range), or proportion (percentage). Continuous variables were analyzed with the Wilcoxon test and proportions were studied with the $\chi^{2}$ test. Associations between variables were calculated with Spearman's correlation coefficient. To evaluate the association of on-admission protein levels with risk of infection, independent of known risk factors, multivariate logistic regression analysis was performed. The classical baseline characteristics and risk factors (age, gender, BMI, randomization, CRP, history of malignancy, cardiac surgery, and modified PRISM score) were considered, together with the on-admission lectin pathway protein levels. Receiver operating characteristic curves were drawn, and area under the curve was calculated to assess the predictive power of on-admission lectin pathway protein and CRP levels for infection. To evaluate the predictive power for the likelihood of early alive discharge from ICU, Cox proportional hazard analysis was performed entering the same risk factors, with nonsurvivors censored beyond the longest staying survivor, ensuring the most stringent analysis and avoiding competing risk between death and earlier discharge (39). Multiple linear regression analysis was performed to assess independent determinants of levels of lectin pathway proteins that appeared important for clinical outcomes. SNP allele frequencies were tested against proportions expected from Hardy-Weinberg equilibrium using the $\chi^{2}$ test.

Demographically comparable cohorts of healthy and critically ill children were selected through propensity score matching, using the SPSS R-menu (version R2.10.1, R Foundation for Statistical Computing) in IBM SPSS Statistics 19 (SPSS, Chicago, IL) $(40,41)$. Propensity scores were estimated by logistic regression, with age, gender, and BMI as continuous covariates. Next, one-to-one nearestneighbor matching was performed by using a caliper of 0.004 .

\section{ACKNOWLEDGMENTS}

We thank the clinical and nursing staff of the pediatric ICU of the Leuven University Hospitals for excellent patient care, protocol complience, and sample handling. The data have in part been presented as a poster at the 25th Annual Meeting of the European Society of Intensive Care Medicine, Lisbon, Portugal, 13-17 October 2012.

\section{STATEMENT OF FINANCIAL SUPPORT}

This work was supported by the TBM program (Toegepast Biomedisch onderzoek met een primair Maatschappelijke finaliteit) of the Institute for Science and Technology, Flanders, Belgium (IWT 070695). C.I. received a Doctoral Fellowship of the Clinical Research Fund of the University Hospitals, Leuven. S.T. was supported by the Danish Council for Independent Research, Medical Sciences. GVdB, by the University of Leuven, receives longterm structural research financing via the Methusalem program, funded by the Flemish Government, and holds an "ERC Advanced Grant" from the Ideas Program of the European Union FP7.

Disclosure: The authors have no conflict of interest to disclose.

\section{REFERENCES}

1. Vlasselaers D, Milants I, Desmet L, et al. Intensive insulin therapy for patients in paediatric intensive care: a prospective, randomised controlled study. Lancet 2009;373:547-56.

2. Robertson CM, Coopersmith CM. The systemic inflammatory response syndrome. Microbes Infect 2006;8:1382-9.

3. Kumpf O, Schumann RR. Genetic variation in innate immunity pathways and their potential contribution to the SIRS/CARS debate: evidence from human studies and animal models. J Innate Immun 2010;2:381-94.

4. Wong HR. Genetics and genomics in pediatric septic shock. Crit Care Med 2012;40:1618-26.

5. Kumar H, Kawai T, Akira S. Pathogen recognition in the innate immune response. Biochem J 2009;420:1-16.

6. Sørensen R, Thiel S, Jensenius JC. Mannan-binding-lectin-associated serine proteases, characteristics and disease associations. Springer Semin Immunopathol 2005;27:299-319.

7. Degn SE, Hansen AG, Steffensen R, Jacobsen C, Jensenius JC, Thiel S. MAp44, a human protein associated with pattern recognition molecules of the complement system and regulating the lectin pathway of complement activation. J Immunol 2009;183:7371-8.

8. Neth O, Hann I, Turner MW, Klein NJ. Deficiency of mannose-binding lectin and burden of infection in children with malignancy: a prospective study. Lancet 2001;358:614-8.

9. Schlapbach LJ, Aebi C, Hansen AG, Hirt A, Jensenius JC, Ammann RA. $\mathrm{H}$-ficolin serum concentration and susceptibility to fever and neutropenia in paediatric cancer patients. Clin Exp Immunol 2009;157:83-9.

10. Schlapbach LJ, Kessler U, Thiel S, et al. M-ficolin in the neonatal period: associations with need for mechanical ventilation and mortality in premature infants with necrotising enterocolitis. Mol Immunol 2009;46:2597603.

11. Vollmer-Conna U, Piraino BF, Cameron B, et al.; Dubbo Infection Outcomes Study Group. Cytokine polymorphisms have a synergistic effect on severity of the acute sickness response to infection. Clin Infect Dis 2008; $47: 1418-25$.

12. Gao L, Barnes KC. Recent advances in genetic predisposition to clinical acute lung injury. Am J Physiol Lung Cell Mol Physiol 2009;296: L713-25.

13. Pollack MM, Patel KM, Ruttimann UE. PRISM III: an updated Pediatric Risk of Mortality score. Crit Care Med 1996;24:743-52.

14. Jenkins KJ, Gauvreau K, Newburger JW, Spray TL, Moller JH, Iezzoni LI. Consensus-based method for risk adjustment for surgery for congenital heart disease. J Thorac Cardiovasc Surg 2002;123:110-8.

15. Degn SE, Jensen L, Gál P, et al. Biological variations of MASP-3 and MAp44, two splice products of the MASP1 gene involved in regulation of the complement system. J Immunol Methods 2010;361:37-50. 
16. Thiel S, Jensen L, Degn SE, et al. Mannan-binding lectin (MBL)-associated serine protease-1 (MASP-1), a serine protease associated with humoral pattern-recognition molecules: normal and acute-phase levels in serum and stoichiometry of lectin pathway components. Clin Exp Immunol 2012;169:38-48.

17. Schlapbach LJ, Aebi C, Fisch U, et al. Higher cord blood levels of mannosebinding lectin-associated serine protease- 2 in infants with necrotising enterocolitis. Pediatr Res 2008;64:562-6.

18. Sallenbach S, Thiel S, Aebi C, et al. Serum concentrations of lectin-pathway components in healthy neonates, children and adults: mannan-binding lectin (MBL), M-, L-, and H-ficolin, and MBL-associated serine protease-2 (MASP-2). Pediatr Allergy Immunol 2011;22:424-30.

19. Fisch U, Zehnder A, Hirt A, et al. Mannan-binding lectin (MBL) and MBL-associated serine protease- 2 in children with cancer. Swiss Med Wkly 2011;141:w13191.

20. Schlapbach LJ, Thiel S, Aebi C, et al. M-ficolin in children with cancer. Immunobiology 2011;216:633-8.

21. Schlapbach LJ, Aebi C, Otth M, Leibundgut K, Hirt A, Ammann RA. Deficiency of mannose-binding lectin-associated serine protease- 2 associated with increased risk of fever and neutropenia in pediatric cancer patients. Pediatr Infect Dis J 2007;26:989-94.

22. Schlapbach LJ, Mattmann M, Thiel S, et al. Differential role of the lectin pathway of complement activation in susceptibility to neonatal sepsis. Clin Infect Dis 2010;51:153-62.

23. Schlapbach LJ, Kjaer TR, Thiel S, et al. M-ficolin concentrations in cord blood are related to circulating phagocytes and to early-onset sepsis. Pediatr Res 2012;71(4 Pt 1):368-74.

24. Frakking FN, Brouwer N, van Eijkelenburg NK, et al. Low mannose-binding lectin (MBL) levels in neonates with pneumonia and sepsis. Clin Exp Immunol 2007;150:255-62.

25. de Benedetti F, Auriti C, D’Urbano LE, et al. Low serum levels of mannose binding lectin are a risk factor for neonatal sepsis. Pediatr Res 2007;61:3258.

26. St Swierzko A, Cedzynski M, Domzalska-Popadiuk I, et al. Mannanbinding lectin-associated serine protease-2 (MASP-2) in a large cohort of neonates and its clinical associations. Mol Immunol 2009;46: 1696-701.

27. Cortesio CL, Jiang W. Mannan-binding lectin-associated serine protease 3 cleaves synthetic peptides and insulin-like growth factor-binding protein 5. Arch Biochem Biophys 2006;449:164-70.
28. Degn SE, Jensenius JC, Thiel S. Disease-causing mutations in genes of the complement system. Am J Hum Genet 2011;88:689-705.

29. Sirmaci A, Walsh T, Akay H, et al. MASP1 mutations in patients with facial, umbilical, coccygeal, and auditory findings of Carnevale, Malpuech, OSA, and Michels syndromes. Am J Hum Genet 2010;87:679-86.

30. Rooryck C, Diaz-Font A, Osborn DP, et al. Mutations in lectin complement pathway genes COLEC11 and MASP1 cause 3MC syndrome. Nat Genet 2011;43:197-203.

31. Iwaki D, Kanno K, Takahashi M, Endo Y, Matsushita M, Fujita T. The role of mannose-binding lectin-associated serine protease- 3 in activation of the alternative complement pathway. J Immunol 2011;187:3751-8.

32. Degn SE, Jensen L, Hansen AG, et al. Mannan-binding lectin-associated serine protease (MASP)-1 is crucial for lectin pathway activation in human serum, whereas neither MASP-1 nor MASP-3 is required for alternative pathway function. J Immunol 2012;189:3957-69.

33. Lukaszewicz AC, Payen D. The future is predetermined in severe sepsis, so what are the implications? Crit Care Med 2010;38(10 Suppl):S512-7.

34. Henckaerts L, Nielsen KR, Steffensen R, et al. Polymorphisms in innate immunity genes predispose to bacteremia and death in the medical intensive care unit. Crit Care Med 2009;37:192-201, e1-3.

35. Thiel S. Complement activating soluble pattern recognition molecules with collagen-like regions, mannan-binding lectin, ficolins and associated proteins. Mol Immunol 2007;44:3875-88.

36. Ytting $\mathrm{H}$, Christensen IJ, Thiel S, et al. Biological variation in circulating levels of mannan-binding lectin (MBL) and MBL-associated serine protease- 2 and the influence of age, gender and physical exercise. Scand J Immunol 2007;66:458-64.

37. Krarup A, Sørensen UB, Matsushita M, Jensenius JC, Thiel S. Effect of capsulation of opportunistic pathogenic bacteria on binding of the pattern recognition molecules mannan-binding lectin, L-ficolin, and $\mathrm{H}$-ficolin. Infect Immun 2005;73:1052-60.

38. Wittenborn T, Thiel S, Jensen L, Nielsen HJ, Jensenius JC. Characteristics and biological variations of $\mathrm{M}$-ficolin, a pattern recognition molecule, in plasma. J Innate Immun 2010;2:167-80.

39. Casaer MP, Mesotten D, Hermans G, et al. Early versus late parenteral nutrition in critically ill adults. N Engl J Med 2011;365:506-17.

40. Heinze G, Jüni P. An overview of the objectives of and the approaches to propensity score analyses. Eur Heart J 2011;32:1704-8.

41. Thoemmes F. Propensity score matching in SPSS. ArXiv: 1201.6385 [online], 2012. 